\title{
Maximizing revenue in airline industry through air cargo operations
}

\author{
Nisara Paethrangsi $1^{1, *}$ \\ ${ }^{1}$ College of Hospitality Industry Management, Suan Sunandha Rajabhat University, Thailand
}

\begin{abstract}
This research aims 1) to identify the impact of pricing strategies on airlines' revenues, 2) to identify the impact of non-pricing strategies on airlines' revenues, 3 ) to explore the significance of revenue management to airlines competitive advantage. The behavioural-demand based pricing, psychological pricing, capacity management and over contract booking strategies are determined as independent variables. A dependent variable is the competitive advantage, and a mediator is revenue management. Primary data was collected from an online survey of 500 airline industry and revenue management strategies personnel; there were only 424 completed questionnaires in return. Results show that larger competitive advantage is associated with non- pricing strategy which is the over contract booking and there is a positive relationship between the psychological pricing and competitive advantage, as compared to the behavioural-demand based pricing and capacity management based strategic approaches.
\end{abstract}

\section{Introduction}

Air cargo revenues are currently dramatically increased, the business is providing support to airlines at a time when passenger revenues collapsed. Revenue increase for air cargo has gained an important strategy of most cargo airlines and passenger airlines [1]. The need for speed in delivering of goods is essential in today new normal life after the Covid -19 pandemic. The main export markets for Southeast Asia nations (ASEAN) are the USA and Europe, with commodities like garments, shoes, electronics and hard-disk drives. Cargo movements from Thailand and CLMV countries (Cambodia, Laos, Myanmar and Vietnam) are on the rise. In the past, revenue from cargo of the passenger airlines business was poor, cargo income was only a small proportion of airline revenues, and the management have not allocated both manpower and capital resources on it. Profit from air cargo did not gain attention and it was often seen as no more than by-product operations to fill belly hold space in the aircraft [2].

Airline industry both passenger airlines and cargo airlines are facing challenges due to many factors that range from economic, social and politics. All Airlines are operating with a small margin about five to seven present only and are forced to seek for extra revenue to survive the business [3]. Therefore, revenue maximizing of air cargo will be a prime

\footnotetext{
*Corresponding author: nisara.pa@ssru.ac.th
} 
requirement and this is increasing necessity, that airline should give proper attention to the operations of air cargo. Population of all ASEAN (Association of Southeast Asian Nations) are estimated 655.51 million inhabitants and generates GDP of approximately 3.11 trillion U.S. dollars, a significant increase from the previous year's [4]. Governments across the region focus on develop the air transportation. The expanding labour force and a rapidly increasing middle class imply the rapid economic growth in Asia.

The modernization of retailing and air transportation services within the Asian region reflects these major shifts in consumer demographics. By year 2036, aviation in ASEAN region is expected to create $\$ 1.7$ trillion in economic activity [5]. However, the predicted loss between Asia-Pacific airlines are expected to lose \$29 billion in 2020 because the airline industry has been affected from the COVID-19 pandemic [6]. Global air cargo markets in 2020 showed a capacity remained unable to meet demand as a result of the loss of belly cargo operations on passenger aircraft that have been parked. Cargo operations of airlines in Asia-Pacific fall by 21.3 percent in the mid-year of 2020 compared to the year earlier [7].

Both passenger airlines and cargo airlines in Thailand, are estimated to support US $\$ 11.4$ billion of GDP in the country [1]. Thailand's air cargo performance, has owned the large investment in transport infrastructure, and was ranked the second in ASEAN, and was the seventh in ASIA, while Singapore is the first in ASEAN. Thai government has extensively invested in transport infrastructure under the 12th National Economic and Social Development Plan, which aims to cut the country's logistics costs to $12 \%$ of GDP by 2021 [8].

Airlines in Asia Pacific account for more than a third of global air freight transportation with strong networks and air cargo operations expertise [6]. During the hard time of global pandemic, airlines in this region have played a key role in carrying medical supplies personal protective equipment (PPE) and other essential goods including vaccines, as passenger aircrafts were grounded thus the capacity was limited. As soon as the economic activity rebounds, demand of global export is increasing and speed of delivery is an important driver, which air cargo can full the valuable goods delivery to satisfy customers. In 2020, number of freight tonne kilometres (FTK) in air cargo was declined of $6.4 \%$. The international air cargo demand fell by $15.5 \%$, whilst offered freight capacity plunged by $24.4 \%$.

Table 1. International Scheduled Service of Asia Pacific Airlines 2019-2020.

\begin{tabular}{|l|c|c|c|c|c|c|}
\hline International & Nov-20 & Nov-19 & \% Change & Jan-Nov 2020 & Jan-Nov 2019 & \% Change \\
\hline Passengers (Thousand) & 1,417 & 30,834 & $-95.4 \%$ & 67,874 & 349,740 & $-80.6 \%$ \\
\hline RPK (Million) & 5,171 & 111,428 & $-95.4 \%$ & 265,600 & $1,277,975$ & $-79.2 \%$ \\
\hline ASK (Million) & 17,392 & 139,384 & $-87.5 \%$ & 426,893 & $1,580,828$ & $-73.0 \%$ \\
\hline Passenger Load Factor & $29.7 \%$ & $79.9 \%$ & $-50.2 \mathrm{pp}$ & $62.2 \%$ & $80.8 \%$ & $-18.6 \mathrm{pp}$ \\
\hline FTK (Million) & 5,710 & 6,437 & $-11.3 \%$ & 54,367 & 65,015 & $-16.4 \%$ \\
\hline FATK (Million) & 8,219 & 10,255 & $-19.9 \%$ & 82,521 & 109,477 & $-24.6 \%$ \\
\hline Freight Load Factor & $69.5 \%$ & $62.8 \%$ & $+6.7 \mathrm{pp}$ & $65.9 \%$ & $59.4 \%$ & $+6.5 \mathrm{pp}$ \\
\hline
\end{tabular}

- RPK $=$ revenue passenger kilometres $/ \cdot \mathrm{ASK}=$ available seat kilometres

- FTK $=$ freight tonne kilometres/ $\bullet$ FATK $=$ available freight tonne kilometres

Time sensitivity and customer personal preferences made the air cargo be a key driver in air transportation, and it also affects airlines' operations strategies [9]. Moreover, commercial passenger airlines continued to face a crisis, with operations remain terrible, so the need for managing cargo operations to maximize revenue is necessary for airlines. The aims of this research are; 1) to identify the impact of pricing strategies on airlines' 
revenues, 2) to identify the impact of non-pricing strategies on airlines' revenues, 3) to explore the significance of revenue management to airlines competitive advantage.

\section{Theoretical and Literature Review}

\subsection{Characteristics of air cargo market and revenue management}

Customers choose various types of transportation mode depends on value of goods, urgency, cost of transport, vulnerability of goods, location of manufacture, weight and density, types of goods as hazardous or not, delivery point accessibility and existence local condition [10]. Although price mechanism plays a critical role in decision, the urgency and life threatening could be the deciding factors. For high value equipment such as musical instruments and aircraft engine parts, air cargo is the answer. In addition, the perishable goods like fresh flowers, fruit and vegetables need to be kept refrigerated in containers while shipping, these benefit to air cargo business.

Price charge of cargo is based on shipment weight, volume and surface modes of transport. Volume or tonne-kms of commodities transport by air categorized into $27 \%$ is a high technology goods, $19 \%$ is capital equipment, $17 \%$ is apparel, textiles and footwear, $16 \%$ is consumer products, 125 intermediate products and $5 \%$ is refrigerated foods [11]. Air cargo is the fastest transportation mode in the world, which is 20 to 30 times faster than going on sea. 5 to 10 times faster than using the train, 7 to 15 times faster than transport by car [12].

As the new normal life of people, the value of time increases. Flying is not only providing a pleasure and a luxury, but also a necessity for work and life. Air transportation is the most safety, it is higher than that of railways, sea travel, and road transportation [13].

\subsection{Behavioural, demand-based pricing and competitive advantage}

Demand-based pricing or behavioural pricing concept is using consumers demand and value perception in setting a price of products or service as central elements [14]. Price fairness is significant matter while the consumers prefer cheaper price, and the companies want to get profits. Most of airlines fear of customers perceived the price is unfair, therefore they provides tools for the forwarders to offer customized price and service quotes.

Nair [15] proposed the vital master plan of pricing and non- pricing revenue maximization and ruthless advantage in the hotel industry, results showed that hotels tend to check the demand based pricing, voluntary product pricing and promotion pricing. This price strategy associated critically with the figure of revenue performance. In this sense; the hypothesis has been proposed as; Hypothesis 1: There is a critical relationship between behavioural demand based pricing and competitive advantage.

\subsection{Psychological pricing and competitive advantage}

Psychological pricing is a price strategy based on the theory that certain prices have a bigger psychological impact on consumers than others. Industry may adopt this psychological price to products, e.g. charm pricing, prestige pricing, buy one get one free, comparative pricing and dynamic pricing [16]. Most of the rate charged for air cargo is done under contracts between freight forwarders and airlines and rate agreements are confidential [11].

Yuen [17] discussed psychological price strategy plays a critical role in economics by guiding the efficient allocation of resources in market-based economies. Research split the 
prices scheme into two groups and the result showed that the quantities sold by stores with high prices do not respond one-for-one to changes in the quantities sold by stores with low prices. The study revealed that consumers generally pay attention to prices when shopping. Many price-conscious consumers go shopping in many places in order to buy lower price products. Airline customers tend to look for the best price from many airlines before buying ticket. Factors concerned price are comparability of service, buyer-seller relation, knowledge of market, transparency and justice and reliability of brands. Thus, the hypothesis is suggested as; Hypothesis 2: There is a critical relationship between psychological pricing and competitive advantage

\subsection{Capacity management and competitive advantage}

Capacity of cargo is an uncertain stowage due to the nature of shipment by air, there are some no-shows, and the amount of passenger baggage is unpredicted. As passengers request a specific flight to travel, cargo shipments customers demand only an origin and destination. As long as the shipment has to deliver at the destination by the time passenger requested, route assignment is flexible. Airline can manage capacity efficiently if the estimation of the cargo show-up rate at departure calculates accurately [18].

Thus, this hypothesis is used to test links between capacity management and the competitive advantage of an airline. Hypothesis 3: There is a critical relationship between capacity management and competitive advantage.

\subsection{Over contract booking and competitive advantage}

Levin \& Nadiek [19] proposed capacity utilizations, price structure and costs associated with accepted bookings. The allotment contracts between airline and freight forwarder are fixed the shipping rate and the amount of reserved capacity. The obligation is allotment will be kept for at least a few months. Many transactions occur in the contract period and airlines gain benefit from effective capacity management which have booked from freight forwarders. Popescu [18] describes the ability to evaluate space utilization, and forecast excess capacity for free sales are crucial impact on overbooking levels and revenue gain on excess.

Wals \& Schinkel [20] discussed relationship between over contract booking and competitive advantage in hotel and airline business that they have positive relationship with each other. Over contract booking is beneficial to both consumers and firms. Therefore; the hypothesis has been suggested as; Hypothesis 4: There is a critical relationship between over contract booking and competitive advantage.

\subsection{Mediation of revenue management between behavioural, demand-based pricing and competitive advantage}

Revenue maximization concept of cargo operations is different from passenger operations concept. Weight and volume generate revenue for cargo management while cabin and passenger management uses dynamic price strategy, that airline charges passengers on same flight differently, depends on a specific prices class is open at a time buying. Similarly to cargo operations, there are various types of goods such as mail, fresh food, live animal, hi-tech devices and even empty space. Thus, the revenue generating of cargo operations does not come from only price of shipment, the cost related to handling, special packaging, capacity management and fuel burning are concerned. The weight, volume, capacity control and profit per $\mathrm{kg}$ of are variable [21]. 
Zhou, Brown, \& Dev [22] surveyed hotel and airline industry demands, their research discovered that there are many price sensitive customers, if a business adapts a price scheme it can get more customers. Research also found larger impacts of pricing to number of customer. It is reasonable to expect that demand based pricing has impact on an airline industry revenue. Hypothesis 5: Revenue management plays as a critical mediator between demands based pricing and competitive advantage

\subsection{Mediation of revenue management between psychological pricing and competitive advantage}

Kharitonova [23] discusses revenue management as a moderator from the research of business intelligence role and analytics within hospitality revenue management, nearly all of revenue tasks are supported by business intelligence and analytics functionalities, Research provided evident that revenue management runs a business with the best performance. Revenue has impact on firm's performance improvement and correlation between psychological pricing and competitive advantage is positive [24].

Therefore, the suggested hypothesis is; Hypothesis 6: Revenue management plays as a critical mediator between psychological pricing and competitive advantage

\subsection{Mediation of revenue management between capacity management and competitive advantage}

Cargo revenue management aims to maximize revenue by mean of managing tariff rates and allotments. Cargo carried on passenger flights is highly uncertain. The volume of cargo may be changed only thirty minutes before flight departs or even no show cargo [11] Not only uncertain volume, air cargo still suffers from the dimension of volume, mass or weight and container positions [25].

Although air cargo revenue management is similar in many ways with other business, there are particular complexities. Capacity forecasting is the key role that carrier must understand how much space they can sell for excess income.

The accuracy of forecasting and available actual cargo capacity for sale relate to revenue and competitive advantage [11]. Hence; the suggested hypothesis is; Hypothesis 7: Revenue management plays a critical mediator between capacity management and competitive advantage.

\subsection{Mediation of revenue management between over contract booking and competitive advantage}

Freight forwarder makes a contract with airline in advance that guarantee certain capacity on many flights at a pre- agree rate. The forwarder can return unrequired capacity to airline up to 72 hours before departure otherwise pay for penalties of $25-100 \%$ of the contract rate [11]. When cargo capacity has been estimated the allotment allocation will be deducted to see the actual remaining.

At this point, an over contract booking is applied; this depends on obligations between freight forwarders and airlines. Same concept as hotel staff will calculate the optimal number of bookings for hotel rooms and proposed of overbookings to the management. Overbooking is a complex process, deeply connected with revenue and yield management. Business must develop service recovery programs specifying the standard procedures that employees have to follow when facing an overbooking [26].

However, there is the relationship of overbooking and competitive advantage with the mediator of revenue management. Thus, suggested hypothesis is, Hypothesis 8: Revenue 
management plays as a critical mediator between over contract booking and competitive advantage.

\section{Research Methodologies}

Methodology in this study is based on a quantitative source of data collection by using Structural Equation Modelling (SEM), where the pricing and non-pricing strategies for revenue management are considered as independent variables and the related variables are behavioural demand based pricing, psychological pricing, capacity management, and over contract booking.

Variable of competitive advantage is studied as a dependent variable and the revenue management is a mediator within the elaborate relations. Complete an online survey. The population in this research is airline industry employee in Thailand, freight forwarder enterprises and personnel of strategic firms.

Purposive sampling was selected, where the respondents are airline employees, supervisors and manager in finance, strategic personnel, business owners who have experience-based knowledge regarding the pricing and non-pricing strategies to gain competitive advantage.

Respondent are 58\% male and $44 \%$ are females. Based on the demographic data, it was shown that 132 participants are less than 25 years, 180 are 25 to 35 years old, 96 are 35 to 45 years old, while 16 of them are more than 45 years old. For experience related field is concerned, the outcomes are $16 \%$ of respondents have less than two years' experience, $42 \%$ with 2 to 5 years' experience, $32 \%$ have 5 to 8 years' experience, and $9.4 \%$ of them have experience more than 8 years. However, these demographic statistics identified that majority of respondents are highly experienced and understand the pros and cons of revenue management strategies.

\section{Results and Analysis}

Table 2 shows, after getting the five-point Likert scale based valid research outcomes, the structural equation modelling and its related tests is predicted average effect of each variables in this statistical analysis (see table 2) [27, 28].

Table 2. Descriptive Statistics.

\begin{tabular}{|c|c|c|c|c|c|c|c|}
\hline & $\mathbf{N}$ & $\begin{array}{c}\text { Mini- } \\
\text { mum }\end{array}$ & Maximum & Mean & Std. Deviation & \multicolumn{2}{|c|}{ Skewness } \\
\cline { 2 - 8 } & Statistic & Statistic & Statistic & Statistic & Statistic & Statistic & Std. Error \\
\hline DemBasP & 424 & 1.00 & 5.00 & 3.2134 & 1.05177 & -.189 & .119 \\
\hline PsychPric & 424 & 1.00 & 5.00 & 3.2842 & .98632 & -.353 & .119 \\
\hline CapMange & 424 & 1.00 & 5.00 & 3.5333 & 1.15071 & -.564 & .119 \\
\hline OverConB & 424 & 1.00 & 5.00 & 3.1989 & 1.20480 & -.259 & .119 \\
\hline RevnMang & 424 & 1.00 & 5.00 & 3.5678 & 1.13637 & -.524 & .119 \\
\hline CompAdva & 424 & 1.00 & 5.00 & 3.3601 & 1.14388 & -.449 & .119 \\
\hline $\begin{array}{c}\text { Valid N } \\
\text { (listwise) }\end{array}$ & 424 & & & & & & \\
\hline
\end{tabular}

This indicates that the psychological pricing and demand based pricing are less deviated from their means position, while the over contract booking and capacity management highly deviate from their means. This shows that competitive advantage factor is mainly affected by the strategies of pricing. Statistics of KMO and Bartlett's test are shown (see table 3) [29]. 
Table 3. KMO and Bartlett's Test.

\begin{tabular}{|c|c|c|}
\hline $\begin{array}{r}\text { Kaiser-Meyer-Olkin Measure of Sampling } \\
\text { Adequacy. }\end{array}$ & $\mathbf{. 8 9 7}$ \\
\hline \multirow{2}{*}{$\begin{array}{c}\text { Bartlett's Test of } \\
\text { Sphericity }\end{array}$} & Approx. Chi-Square & 6002.549 \\
\cline { 2 - 3 } & $\mathrm{df}$ & 153 \\
\cline { 2 - 3 } & Sig. & .000 \\
\hline
\end{tabular}

The statistics show that all the Kaiser-Meyer-Olkin measures are within their threshold range with an appropriate significance level, that represents this model is a good fit to test the hypothesis of this research.

Table 4. Rotated Component Matrix.

\begin{tabular}{|l|c|c|c|c|c|c|}
\hline & \multicolumn{7}{|c|}{ Component } \\
\cline { 2 - 7 } & $\mathbf{1}$ & $\mathbf{2}$ & $\mathbf{3}$ & $\mathbf{4}$ & $\mathbf{5}$ & $\mathbf{6}$ \\
\hline DB1 & & .829 & & & & \\
\hline DB2 & & .890 & & & & \\
\hline DB3 & & .846 & & & & \\
\hline PP1 & & & & & & .728 \\
\hline PP2 & & & & & & .792 \\
\hline PP3 & & & & & & .803 \\
\hline CM1 & & & & & .816 & \\
\hline CM2 & & & & & .867 & \\
\hline CM3 & & & & & .809 & \\
\hline OC1 & .841 & & & & & \\
\hline OC2 & .869 & & & & & \\
\hline OC3 & .859 & & & & & \\
\hline RM1 & & & .844 & & & \\
\hline RM2 & & & .847 & & & \\
\hline RM3 & & & .859 & & & \\
\hline CA1 & & & & .796 & & \\
\hline CA2 & & & & .797 & & \\
\hline CA3 & & & & .832 & & \\
\hline
\end{tabular}

Table 5. Convergent and Discriminant Validity.

\begin{tabular}{|c|c|c|c|c|c|c|c|c|c|}
\hline & CR & AVE & MSV & RM & DB & PP & CM & OC & CA \\
\hline RM & 0.907 & 0.765 & 0.340 & $\mathbf{0 . 8 7 5}$ & & & & & \\
\hline DB & 0.905 & 0.760 & 0.388 & 0.487 & $\mathbf{0 . 8 7 2}$ & & & & \\
\hline PP & 0.819 & 0.603 & 0.388 & 0.583 & 0.623 & $\mathbf{0 . 7 7 7}$ & & & \\
\hline CM & 0.901 & 0.752 & 0.289 & 0.524 & 0.471 & 0.530 & $\mathbf{0 . 8 6 7}$ & & \\
\hline OC & 0.922 & 0.797 & 0.507 & 0.293 & 0.319 & 0.334 & 0.505 & $\mathbf{0 . 8 9 3}$ & \\
\hline CA & 0.934 & 0.825 & 0.507 & 0.454 & 0.401 & 0.508 & 0.538 & 0.712 & $\mathbf{0 . 9 0 8}$ \\
\hline
\end{tabular}

Based on data, the rotated component matrix values of tested items are greater than 0.7 (standard value) and within the threshold range, it represents all the items are effectively uploaded on the tested model and no more difficulty remains in the uploading process.

As the validity based descriptive outcomes, the average variance extracted values of each tested item is greater than 0.5 , and all the composite reliability values are also higher than 0.7 . No occurrence of any convergent validity issue within this mechanism. The bold letters based outcomes show the non-occurrence of discriminant validity issues on the tested variables, because each item has its own identity and different from the other ones. The model fit indices based information is given as. 
Table 6. Model Fit Indices.

\begin{tabular}{|l|c|c|c|c|c|}
\hline CFA Indicators & CMIN/DF & GFI & IFI & CFI & RMSEA \\
\hline Threshold Value & $\leq 3$ & $\geq 0.80$ & $\geq 0.90$ & $\geq 0.90$ & $\leq 0.08$ \\
\hline Observed Value & 2.330 & 0.932 & 0.973 & 0.973 & 0.056 \\
\hline
\end{tabular}

Based on data, all the CFA indicators' values are within their threshold range. Like the RMSEA observed value is 0.056 (lower than 0.08), both outcomes of IFI and CFI are 0.973 (greater than 0.90), the GFI value is 0.932 (greater than 0.80 ), and the CMIN/DF value is 2.33 (lower than 3 ). Its graphical representation is shown (see figure 2).

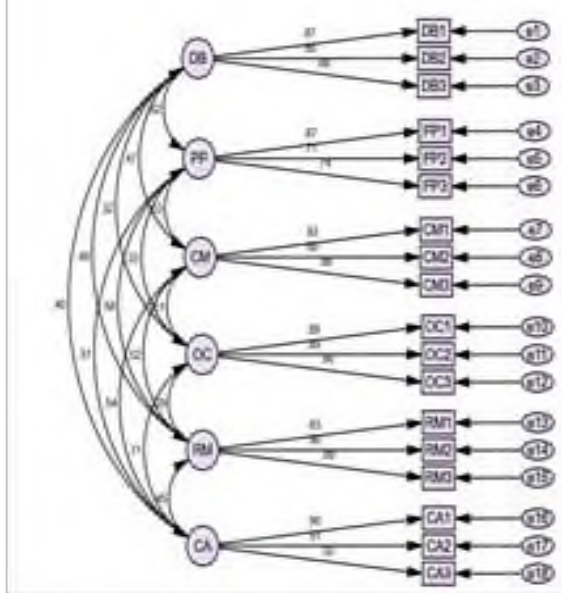

Fig. 2. CFA.

Table 7. Structural Equation Modeling.

\begin{tabular}{|c|c|c|c|c|c|}
\hline Total Effect & OverConB & CapMange & PsychPric & DemBasP & RevnMang \\
\hline RevMangP & .048 & $.256^{* *}$ & $.305^{* *}$ & $.124^{* *}$ & .000 \\
\hline CompAdva & $.522^{* *}$ & $.146^{* *}$ & $.198^{* *}$ & .052 & $.159^{* *}$ \\
\hline Direct Effect & OverConB & CapMange & PsychPric & DemBasP & RevMangP \\
\hline RevMangP & .048 & $.256^{* *}$ & $.305^{* *}$ & $.124^{* *}$ & .000 \\
\hline CompAdva & $.514^{* *}$ & $.105^{* *}$ & $.150^{* *}$ & .032 & $.159^{* *}$ \\
\hline $\begin{array}{c}\text { Indirect } \\
\text { Effect }\end{array}$ & OverConB & CapMange & PsychPric & DemBasP & RevMangP \\
\hline RevMangP & .000 & .000 & .000 & .000 & .000 \\
\hline CompAdva & .008 & $.041^{* *}$ & $.048^{* *}$ & $.020^{* *}$ & .000 \\
\hline
\end{tabular}

The SEM indicates that there is a critical relationship between the tested variables, like one percent change in the over contracting booking cause $4.8 \%$ deviation in the revenue management and 52\% deviation in the competitive advantage. While these factors are affected by $26 \%$ and $15 \%$ through capacity management, $30 \%$ and $20 \%$ through psychological pricing and $12.4 \%$ to $5.2 \%$ through behavioural, demand based pricing. So the individual revenue management performance caused a $16 \%$ change in the outcomes of competitive advantage (see figure 3 ). 


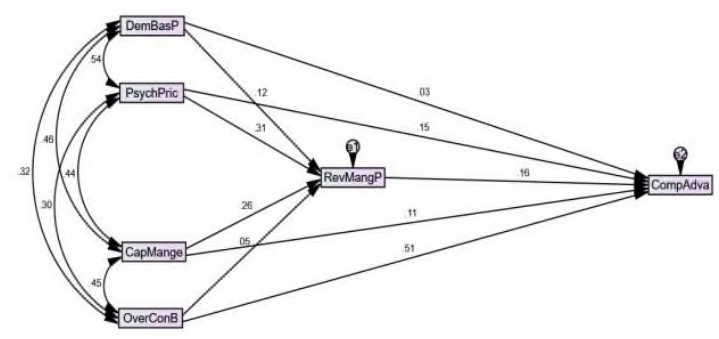

Fig. 3. SEM.

\section{Conclusions}

Discussion, the SEM-based statistics have been analysed, and it showed that there is a highly relation between the over contract booking and competitive advantage, and between the physiological pricing and revenue management in airline industry in Thailand. Nair [15] revealed the dimensions of pricing and non-pricing strategies adopted in business on the approach and indicated that hotels should closely monitor demand based pricing, optional product pricing, promotional pricing, and psychological pricing among pricing strategies. In addition, many researches have been made by the scholars to evaluate the revenue generated strategies on airlines. Research outcomes concluded that there are many variables influence airline revenues increase strategies such as space control, dynamic pricing, customer expectation meet, service quality and variety of service, which airlines need to adopt those strategy to gain competitive advantage [30-36].

Conclusion, many studies have identified important drivers of pricing and non-pricing strategies in cargo operations of air cargo airlines, but few have analysed the performance in passenger airlines, in maximizing revenue through the cargo operations. This study showed important relationship between the pricing, non-pricing strategy and the gaining of competitive advantage. A significant test statistic in this research provides evident that, the impact of pricing based strategy on airlines' revenues is a psychological pricing strategy and the impact of non-pricing based strategy is the over contracting booking strategy. Certainly the SEM analysis concluded that other variables are insignificant effect on the airline industry revenue and the competitive advantage of airlines industry.

\section{Recommendations and Future Works}

Revenue maximizing strategies can be drawn from this research to benefit the strategic managers in enhancing company performance. The research proposal can be used to create new direction of airlines' revenue management. As any limitation in the research, this study leaves gap for further study in logistics and all cargo airlines.

\section{References}

1. IATA, Cargo operations (2020)

2. S. Shaw, Airline Marketing and Management Ashate (2011)

3. S. Holloway, Straight and Level Practical Airline Economics (Ashgate, 2008)

4. Statista, Total Population of ASEAN Countries from 2010 to 2020 (2021)

5. ATAG, Air Transport Action Group (2020)

6. AAPA, https://www.aapairlines.org (2020) 
7. ASEAN Aviation, IATA: May air cargo shows slight pickup (2020)

8. Mordor Intelligence, Freight and Logistics Market - Growth (2020)

9. J.H. Choi, Y.H. Park, Journal of Sustainability 12, 20 (2020)

10. Seymour et al., J. of Tourisme Futures 3, 1 (2017)

11. P.S. Morrell, T. Klein, Moving Boxes By Air (Routledge, 2018)

12. B. Registe, The Chicago School of Professional Psycho (ProQuest Dissertations, 2016)

13. CAAT, State of Thai Aviation Industry 2019 (2020)

14. P. Mill, ProQuest Dissertations and Thèses (2017)

15. G.K. Nair, Intl. J. of Hospitality Mgnt. 82, 287-297 (2019)

16. P. Boachie, Five Strategies of Psychological Pricing (2016)

17. J.J.H. Yuen, Vanderbilt University (ProQuest Dissertations, 2018)

18. A. Popescu, Georgia Institute of Technology (ProQues Dissertations, 2006)

19. Y. Levin, M. Nediak, Operations Research (Queen's University, 2012)

20. F. Wals, M. Schinkel, Intl. J.of Industrial Orgz. 61, 572-589 (2018)

21. K. Pak, R. Dekker, J. of Econ Literature 13 (2004)

22. E.V. Andreeva et al., Actual Problems of Economics 183(9), 220-227 (2016)

23. A. Kharitonova, University of Nevada (ProQuest Dissertations, 2019)

24. R. Kamasak, C. Cansever, Intl. J. of Bs. Tour.\& Appl. Sci. 7(1), 39-43 (2019)

25. R.G. Kasilingam, Européen J. of Opérationnel Resarci 96 (1996)

26. D.S. Ushakov et al., Geojournal of Tourism and Geosites 27(4), 1429-1438 (2019)

27. M. Civelek, Essentials of structural equation modeling (2018)

28. J. Wang, X. Wang, Structural equation modeling: Applications using Mplus (John Wiley \& Son, 2019)

29. D. Napitupulu et al., J. of Phys. Con.Series (2018)

30. S. Shihab, Iowa University (ProQuest Dissertations, 2020)

31. K. Charernnit, K. Kankaew, J.of Critical Reviews 7(13), 2039-2042 (2020)

32. Yu. Shunan et al., J. of Air Transp. Mgnt. 75, 9-15 (2019)

33. N. Paethrangsi, Intl. Acad. Multiplry. R. Conf. in Malta (2020)

34. Qin Han, National University of Singapore (ProQuest Dissertations and Theses, 2015)

35. K. Kankaew, E3S web of Conferences 175, 13033 (2020)

36. R. Waramontri, Actual Econ. local solutions for globl. Challges, 418-425 (2019) 